\title{
Pulmonary agenesis, pulmonary aplasia and pulmonary hypoplasia: Can you differentiate them?
}

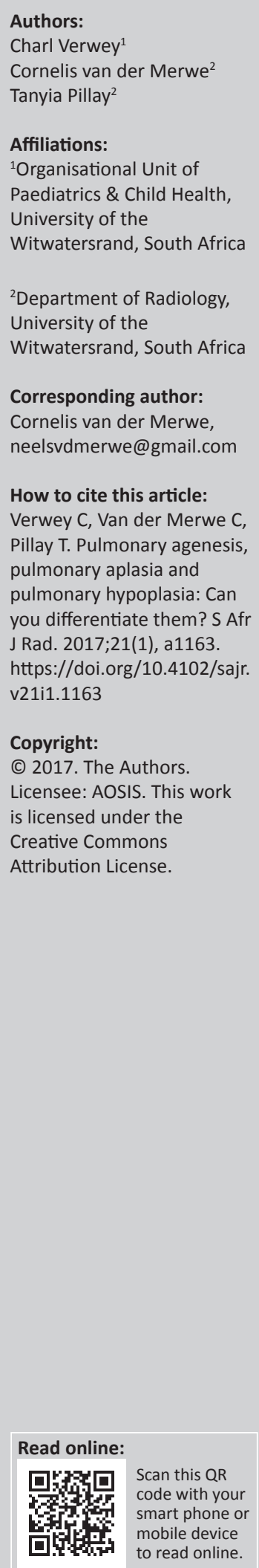

\section{Copyright:}

(c) 2017. The Authors. Licensee: AOSIS. This work is licensed under the Creative Commons Attribution License.

Background: Pulmonary underdevelopment is categorised into three groups: pulmonary agenesis, pulmonary aplasia and pulmonary hypoplasia. Pulmonary agenesis is the complete absence of the lung parenchyma, bronchus and lung vasculature. Pulmonary aplasia is characterised by the absence of the lung parenchyma and pulmonary vasculature; however, there is a rudimentary blind-ending bronchus present. Pulmonary hypoplasia is defined by the presence of a bronchus and rudimentary lung parenchyma with a reduction in number and size of airways, alveoli and pulmonary vasculature.

Objective: This is an educational poster in the form of a quiz to identify and differentiate the type of pulmonary underdevelopment according to imaging features, associations and aetiology.

Method: Radiological images of patients with pulmonary underdevelopment, who presented to the Paediatric Department of Chris Hani Baragwanath Academic Hospital, were selected.

Conclusion: It is reported that up to $50 \%$ of patients with pulmonary agenesis and pulmonary aplasia have at least one other systemic congenital abnormality. Secondary pulmonary hypoplasia is more common than primary pulmonary hypoplasia and the aetiology is often evident on the imaging series. Radiological imaging is essential in differentiating the type of pulmonary underdevelopment.

Note: A selection of conference abstracts: RSSA/SASPI Paediatric Imaging Congress, 03-06 November 2016, Spier Estate, Stellenbosch, South Africa. Faculty collaborators: Professor Kassa Darge (Body Imaging, University of Pennsylvania, Philadelphia, USA), Professor Edward Lee (Thoracic Imaging, Harvard University, USA), Professor Beverley Newman (Cardiac Imaging, Stanford University, California, USA), Professor Kimberly Applegate (Image Gently and Body Imaging, Emory University, Atlanta, USA) and Professor Savvas Andronikou (Thoracic Imaging, University of Bristol, UK) supported by South African Paediatric Radiologists, co-ordinated by Dr Jaishree Naidoo, President of the African Society of Paediatric Imaging and Head of Division of Paediatric Radiology, Charlotte Maxeke Johannesburg Academic Hospital. 